\title{
LA MATERNIDAD SIN DOLOR
}

\section{Doctor Gustavo Isaza Mejía}

Trabajo realizado en la cátedra de Ginecología del Profesor Pedro Nel Cardona C. (Medellín - Colombia) (*)

Este método nació en Rusia y se basa en las experiencias de Pavlov; ha llamado la atención del mundo médico y suscitado gran interés hasta el punto de que ha sido aceptado ya en los paises europeos, en la India, la China; en Rusia es obligatorio por el Decreto 142 de julio de 1951; y todas las mujeres son be. neficiadas.

Según Velvosky, el método Psicoprofiláctico no trata de curar los dolores del parto o de atenuarlos sino de suprimirlos totalmente.

La originalidad de este método está en el hecho de emplear como agente terapéutico, no una droga, sino la palabra.

Imposible sería imaginarse uno que pueda proponerse a la mujer una actitud consciente durante el parto si se considera de acuerdo con Bichat, ilustre médico francés del siglo pasado, que no hay ninguna relación nerviosa entre la corteza cerebral y los organos internos y pensáramos que el útero funciona aisladamente por su propia cuenta.

Según los estudios de Pavlov por el contrario, se demostró que la unidad del organismo y del medio exterior es un hecho y que es a la corteza cerebral a la que le toca el gran papel de comandante supremo; es en efecto el cerebro el que comanda todas las funciones. Cada porción del organismo tiene su representación en una célula cerebral, la cual es su motor, por lo tanto ningún órgano escapa al control cerebral.

También probaron estos autores que en el interior de las vísceras existen receptores nerviosos especializados (Interoceptores), capaces de ser estimulados por las modificaciones del medio interior, y que los impulsos salidos de estos interoceptores

(*) Trabajo presentado al Tercer Congreso Nacional de Obstetricia y Ginecología en diciembre de 1957 en Ibagué. 
pueden llegar a la corteza cerebral, (necesaria a la formación de los reflejos condicionados), siendo esta corteza el sitio de una representación del medio interior, pueden por lo tanto estos impulsos salidos del medio interno, dar origen a reflejos condicionados interoceptivos. Ejemplo: irrigando la mucosa gástrica de un perro con agua tibia, y reforzando este estímulo con la presencia de la alimentación, se puede después de algún tiempo formar el reflejo condicionado interoceptivo al agua tibia solamente. El reflejo condicionado en este caso consiste en que, al cabo de algunas repeticiones de la misma experiencia, es suficiente irrigar la mucosa del estómago con agua tibia solamente, para que el perro sienta la sensación del hambre, salive. En el cerebro del perro se formó por acostumbramiento, una ligación entre la sensación del hambre y la sensación térmica producida por el agua tibia.

Así comprendemos el papel de la corteza en la formación de los reflejos condicionados de los órganos internos, reflejos intero. ceptivos.

Esta fisiología cortico-visceral es la que nos explica la com. prensión del dolor del parto y de su profilaxia.

Los reflejos condicionados interoceptivos presentan la particularidad siguiente: son muy lentos en formarse, pero una vez formados, son más estables.

Esto corresponde a las características del medio interior que se modifican difícilmente porque es relativamente estable.

En la escala humana interviene un factor nuevo: la palabra, el lenguaje, base del pensamiento y del comportamiento superior del hombre. La palabra es la base de la educación que permite acumular las experiencias de otros hombres. Su importancia aparece claramente en el miedo al dolor propio a la mujer y que se presenta también en las primíparas.

Con la ayuda de la palabra se puede obrar directa o indirectamente sobre las funciones orgánicas. Ejemplo: por medio de la sugestión o la hipnosis, se puede provocar la embriaguez alcohólica haciendo ingerir a la persona agua declarándole que es vi. no; no solamente se producen los signos exteriores de la embriaguez sino también las modificaciones nerviosas correspondientes.

La palabra puede hacer aparecer sensaciones dolorosas o puede borrarlas completamente.

En el hombre, la palabra puede servir de exitante condicio. nal muy poderoso para dar lugar al dolor o hacerlo desaparecer 
ejemplo: Colocar un tubo con agua caliente sobre la piel de una persona hasta producirle dolor, al cabo de algunas experiencias, es suficiente decir: voy a colocar el tubo, para que la persona en experimentación comience a sentir el dolor.

\section{El dolor}

Biológicamente el dolor es una reacción de defensa ante cualquier causa lesionante; representando uno de los mecanismos neurológicos más primitivos al servicio del instinto de conservación.

Con la aparición en la especie humana de la capacidad de interpretar situaciones, el dolor adquiere la modalidad ps'quica que le permite al hombre prevenir adaptaciones a sucesos que él interpreta lesionantes.

El dolor durante el parto es uno de tantos, que absorbe esta dinámica del instinto de conservación.

Una vez convencida la madre de que su integridad como unidad viviente permanece a salvo durante el parto, ella dejará de anticiparse y se adaptará dentro de un nuevo principio de realidad que acepta confiadamente.

La tendencia a la defensa contra el dolor como integrante de la necesidad instintiva de conservación no es la que interesa modificar; es el robustecimiento psíquico del Yo del paciente el que debe hacerse fuerte para que confíe en las defensas naturales que le fueron dadas.

\section{El miedo al dolor}

El miedo al dolor asociado a la idea del parto mismo, ha llegado a ser sinónimo del dolor. Este miedo al sufrimiento es propio del género humano, capaz de preveer el dolor antes de que se produzca, gracias al pensamiento superior que reposa sobre el lenguaje.

Este temor está lígado no solamente a las contracciones uterinas, sino al parto en sí mismo; miedo a las complicaciones, al forceps, a la anestesia, a la propia vida, a la hemorragia, la infección, temor por la vida del niño, las dificultades que él atañe, su porvenir. El mandato bíblico, mal interpretado, la tradición que ha sido capaz de hacer del dolor en el parto un fenómeno de las masas. 
Durante el parto, las palabras del partero pueden ser nefas. tas cuando pregunta: ¿señora tiene usted los dolores muy intensos? ¿a qué horas le empezó el dolor?

Estos hechos y estas palabras crean en el cerebro de la ma. dre ligaciones duraderas, verdaderos reflejos dolorosos que se hacen más intensos a medida que se repiten porque hacen bajar el límite de sensibilidad cerebral a causa del estado angustioso, Schok emocional repetido.

Anteriormente la madre no participaba en el parto sino con el dolor, su papel era completamente pasivo entreguismo; el marido esperaba afuera, fumando, tomando café, excitado también hasta que llegaban con la noticia.

Con el método psicoprofiláctico, la madre y también el padre que puede asistir al parto, participan en él de manera activa, dirigiendo cada uno de sus momentos; porque saben, tienen conocimiento perfecto de lo que está sucediendo.

El miedo al dolor, emoción condicional, adquirido en el curso de la vida social (miedo ligado a las diferentes manifestaciones de la vida sexual y al porvenir del individuo), hiere los sentimientos maternos y baja el nivel o límite de sensibilidad cerebral a los dolores.

Numerosos reflejos condicionados intervienen aún, formados tanto en el período que precede al embarazo y el parto, como durante el mismo parto.

El cuadro clínico del dolor durante el parto resulta de los reflejos desencadenados en los diversos niveles del sistema nervioso por los influjos centrípetos, y que provienen de los receptores del dolor y de otros receptores de los órganos genitales internos, reflejos que repercuten sobre todas las funciones del organismo. El Tálamo interviene en parte pero es en definitiva la corteza cerebral la que regula y domina el conjunto de estos reflejos y así determina la intensidad del dolor.

El método Psicoprofiláctico se propone destruir las estrati. ficaciones emocionales y estos reflejos condicionados del dolor o mejor de inhibirlo completamente, tratando por lo tanto de obtener un parto sin dolor.

Estos reflejos condicionados desfavorables son inhibidos por medio de la palabra (educación durante las clases), de lo cual resulta la formación de nuevos reflejos condicionados favorables que suben el límite de sensibilidad cerebral y se oponen a la percepción o interpretación errónea de la contracción uterina. 
El método psicoprofiláctico se opone a la hipnosis por su carácter educativo y activo haciendo un llamado a la conciencia de la madre la cual en todo momento se encuentra en pleno uso de sus facultades, es consciente, directiva, activa.

El método no presenta ningún peligro, antes por el contrario grandes ventajas para la madre y el niño; acortamiento del trabajo y del período expulsivo, disminución de las complicaciones obstétricas, disminución de la asfixia del recién nacido, de los trastornos de la lactancia.

El Método Inglés de Read, trata no de suprimir el dolor, sino de disminuirlo, sus bases son empíricas, da gran importancia a ciertos ejercicios gimnásticos adecuados, si, pero mirados bajo un punto de vista independiente de la corteza cerebral; es muy diferente al método psicoprofiláctico en la teoría y en la práctica, sus resultados son diferentes.

\section{Ventajas del Método}

El Profesor Lamaze, de París, indica las ventajas siguientes:

1a El edema del cuello parece haber desaparecido.

$2^{\mathrm{a}}$ La aplicación del Forceps se ha hecho menos frecuente, se ha reducido al minimo, $3.5 \%$ y se hace en mejores condiciones.

3a El periné será mejor protegido (por la relajación de los músculos perineales).

$4^{\text {a }}$ Episiotomías $7.3 \%$.

5a El alumbramiento es más normal y rápido, las hemorragias del alumbramiento llegan al $2.7 \%$ solamente.

6. El schok obstétrico parece suprimido.

7a Los días del post-parto son excelentes; todas las madres practican el levantamiento precoz y acusan un bienestar físico y psíquico en todo momento.

8a Una corteza cerebral agotada, repercutirá sobre la lactancia (fenómeno que está directamente bajo la dependencia de los reflejos condicionados); por lo tanto, el parto sin dolor mejora notablemente dicha función.

\section{Ventajas sobre el niño}

Debido a la disminución de Forceps y la casi ausencia de as. fixia fetal, se han visto desaparecer las encefalopatías traumáticas por asfixia cerebral las cuales tienen como consecuencia la disminución del número de epilépticos y otras neuropatías. 
Esta repercusión sobre el porvenir del niño es de grandes proporciones; y representa un argumento de gran peso para que el Estado, celoso y cuidadoso del porvenir de los ciudadanos, consagre sus fuerzas a la extensión del método Psicoprofiláctico por todos los lugares del país.

El porvenir del niño nacido sin dolor, será modificado; el niño es más tranquilo, más despierto, la curva de peso es mejor.

También la madre que hace la preparación, será más consciente, comprensiva; su hogar será más feliz, habrá más armonía, el temor a nuevos embarazos será menor. Se disminuirán totalmente los abortos criminales; y los abortos de origen desconocido en los cuales se ha descubierto como causa una gran influencia del psíquismo de la futura madre (abortos psíquicos).

El parto sin dolor ayudará a la desaparición de la noción de sexo débil y contribuirá a hacer a la mujer realmente igual al hombre.

\section{Nuestra experiencia}

Desde nuestro regreso de Europa donde estudiamos el método Psicoprofiláctico al lado del Profesor Lamaze, hemos preparado en nuestra escuela, 80 señoras de las cuales 50 han verificado su parto con los resultados siguientes:

25 partos sin el más mínimo dolor.

10 partos con dolores soportables que no necesitan anestesia.

15 partos con dolor en el último período que hizo necesaria la aplicación de anestesia.

\section{Explicaciones}

Las estadísticas de Europa y Rusia dan el 70\% de éxito total, el $25 \%$ regular, y $5 \%$ fracasos solamente.

Entre nosotros los fracasos, por lo demás relativos, es mayor el $15 \%$. Decimos relativos porque las madres si bien no se libra. ron de los peligros de la anestesia, si obtuvieron como ellas mismas lo atestiguan grandes beneficios durante su embarazo; me. joría o curación total de los trastornos simpáticos de la gestación. Náuseas, vómitos, dolores lumbares, calambres, etc., y sobre todo, lo más interesante es la verdadera transformación que se verifica de sus sistemas nerviosos; las madres se hacen más tranquilas, serenas, dueñas de sí mismas y pierden por completo el te- 
mor al parto, lo que contribuye a que su vida sea más amable y su hogar más feliz.

Además, el dolor solamente se presentó al final del parto en el período expulsivo, habiendo transcurrido en muy buenas condiciones todo el proceso del trabajo que es el más prolongado.

Como dijimos arriba atribuimos los fracasos a los hechos siguientes:

a) El método aún no es perfecto $100 \%$.

b) A la falta de colaboración por parte de nuestro ambiente, poco culto y desconfiado que con frases inconvenientes y maliciosas destruyen lentamente la labor verificada en las clases.

c) La atención de la madre durante el parto que tiene que ser de acuerdo con el método enseñado, para lo cual se necesitan tres condiciones:

1a Conocimiento perfecto del método por parte de los asistentes: médicos, enfermeras y demás personal de las clínicas. Esto es condición absoluta y que no permite excepciones.

$2^{\mathrm{a}} \mathrm{Fe}$ absoluta, total sin vacilaciones del personal asistencial.

$3^{\text {a }}$ Asistencia y ayuda permanente durante todo el tiempo que dura el parto, y no el abandono total o casi total en que se deja a la madre generalmente y que hace naturalmente sembrar el terror y la angustia desencadenando los reflejos desfavorables que con tanto trabajo se habían logrado borrar de su cerebro durante la preparación psicológica.

4 a Solamente 20 casos fueron atendidos durante el parto de acuerdo con el método y 12 no presentaron ningún dolor, 2 llegaron al período expulsivo sin dolor, pero se recurrió a la anes. tesia por aplicación de forceps, los otros 6 casos lograron llegar hasta la dilatación de 8 centímetros sin dolor y solamente lo experimentaron al final del período de dilatación y durante el período expulsivo; pero sin necesidad de recurrir a la anestesia. 